\title{
Residual Static Strength of Tubular T-Joints with Fatigue Surface Cracks
}

\author{
Jian-Jun Wei ${ }^{1}$ and Sheng-zhi Song ${ }^{*}, 2$ \\ ${ }^{1}$ Department of Construction Engineering, Changzhou Institute of Engineering Technology, 213164, Changzhou, \\ Jiangsu, China \\ ${ }^{2} R \& D$ Centre of Jiangsu Construction Safety and Disaster Mitigation, Jiangsu Jianzhu Institute, Xuzhou, 221116, China
}

\begin{abstract}
To study the influence of surface fatigue cracks on the static strength of circular tubular T-joints, experimental tests on four full-scale circular tubular T-joints are carried out. Firstly, surface fatigue cracks are prefabricated by fatigue test in three circular tubular T-joints. Thereafter, experimental tests on the static strength of all the circular tubular T-joints with and without fatigue cracks under axial tension are carried out. Through the comparative analysis, the influences of the fatigue crack on the failure mode and the static strength of circular tubular T-joints are concluded.
\end{abstract}

Keywords: Experimental study, fatigue surface cracks, residual static strength, tubular T-joint.

\section{INTRODUCTION}

Tubular joints have been widely used in offshore structures, bridge structures, space structures and so on, due to their beautiful configurations, excellent mechanical properties and high strength-weight ratio. However, the service environment of these structures is very bad and special, so they often suffer from the cyclic loadings (such as sea wave, sea wind, earthquake and tide). Due to that there is obvious stress concentration phenomenon at the intersection position of chord and brace, the failure of tubular joint often performs that the fatigue cracks occur there. Propagating of fatigue cracks can decrease the stiffness of joint. Which may causes that the joint occurs brittle fracture at the crack position, and then it is possible for the structure to collapse ultimately. Thus, it is necessary and meaningful to study the static strength of tubular $\mathrm{T}$-joint with fatigue surface cracks.

Recently, the main researches of tubular joints are mainly focused on static study, quasi-static study and fatigue property by scholars. However, the researches of residual static strength of tubular joints with fatigue surface cracks are much less. Yang [1] had done the experiment of tubular T-joints with through cracks. It is found that the static strength of cracked specimen decreases by $25 \%$ and $10 \%$ than that of uncracked specimen under tension and compression respectively, and the failure mode is brittle fracture failure. The researchers [2-7] had done some experimental study on the tubular T-joints with artificial notch cracks, and verified the reliability of different kinds of FAD curves. Due to that the cracks were notched by hand, it could not response the actual fatigue surface cracks.

In this paper, the fatigue surface cracks of tubular joints are prefabricated by fatigue test. Base on the contrastive analysis of cracked and uncracked specimens, the failure mode and static performance are clarified.

\section{EXPERIMENTAL INVESTIGATION}

The geometry and some normalized geometrical parameters commonly used for describing a tubular T-joint are shown in Fig. (1).

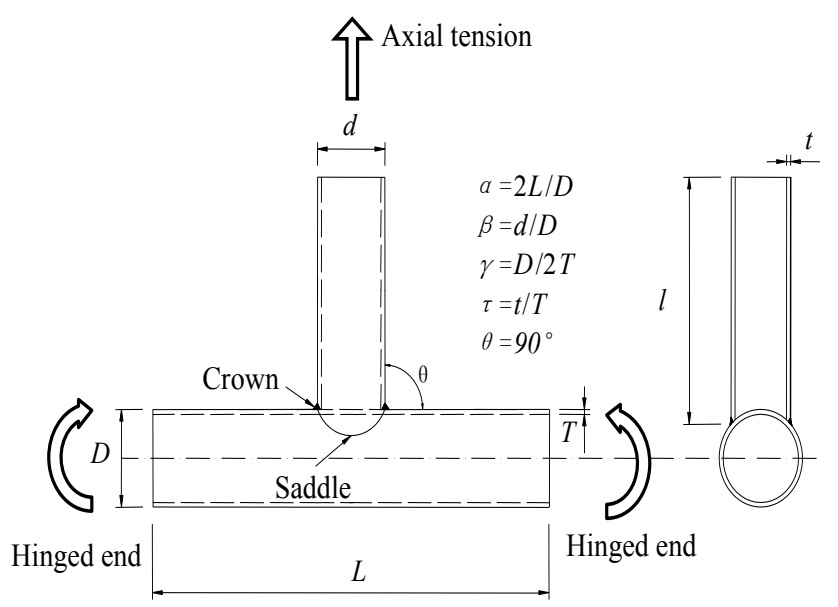

Fig. (1). Geometry of circular tubular T-joint.

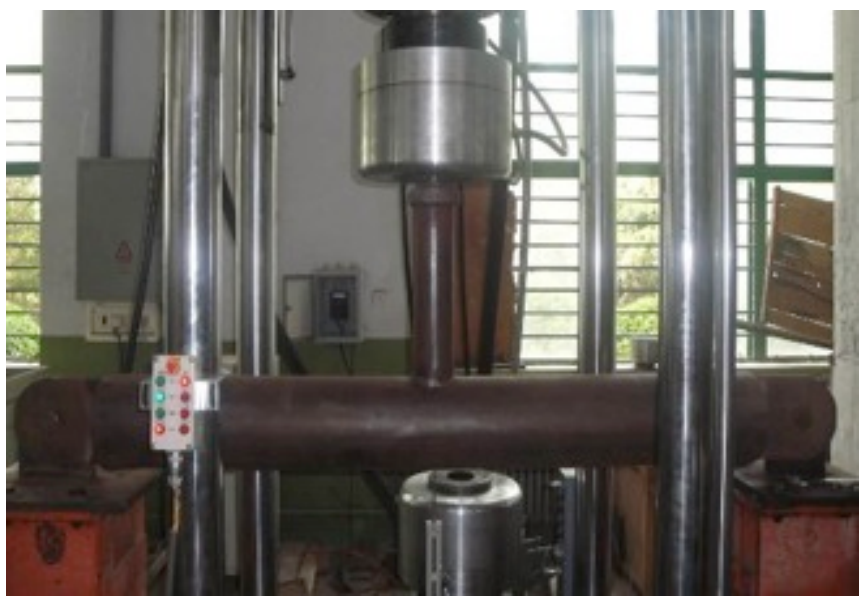

Fig. (2). Test rig. 
Table 1. Geometric parameters of specimens.

\begin{tabular}{|c|c|c|c|c|c|c|c|c|c|}
\hline Model & Type & $\mathbf{L ~ ( m m )}$ & $\mathbf{L}(\mathbf{m m})$ & $\mathbf{D}(\mathbf{m m})$ & $\mathbf{d}(\mathbf{m m})$ & $\mathbf{T}(\mathbf{m m})$ & $\boldsymbol{\beta}$ & $\boldsymbol{\gamma}$ & $\boldsymbol{\tau}$ \\
\hline \hline M-A1 & Cracked & 2000 & 300 & 159 & 45 & 8 & 0.28 & 9.9 & 0.75 \\
\hline M-A2 & Uncracked & 2000 & 300 & 159 & 45 & 8 & 0.28 & 9.9 & 0.75 \\
\hline M-B1 & Cracked & 2000 & 400 & 180 & 133 & 8 & 0.739 & 11.25 & 0.75 \\
\hline M-B2 & Uncracked & 2000 & 400 & 180 & 133 & 8 & 0.739 & 11.25 & 0.75 \\
\hline
\end{tabular}

Table 2. Material properties of steel tube.

\begin{tabular}{|c|c|c|c|c|}
\hline Model & Elastic Modulus (GPa) & Yield Strength (MPa) & Ultimate Tensile Strength (MPa) & Elongation \\
\hline \hline M-A & 200 & 318 & 573 & $23.45 \%$ \\
\hline M-B & 171.8 & 390 & 560 & $16.6 \%$ \\
\hline
\end{tabular}

Two groups (M-A and M-B) of specimens are fabricated, and the geometric parameters of the two groups of specimens are listed in Table 1. Each group includes two specimens (uncracked and cracked). The fatigue surface cracks of specimens are prefabricated on the fatigue test machine (as shown in Fig. 2). Afterwards, all of specimens are carried out the static strength test under axial tension. The material properties of steel tubes are tested by uni-axial tensile test (as shown in Fig. 3), and all of them are listed in Table 2.

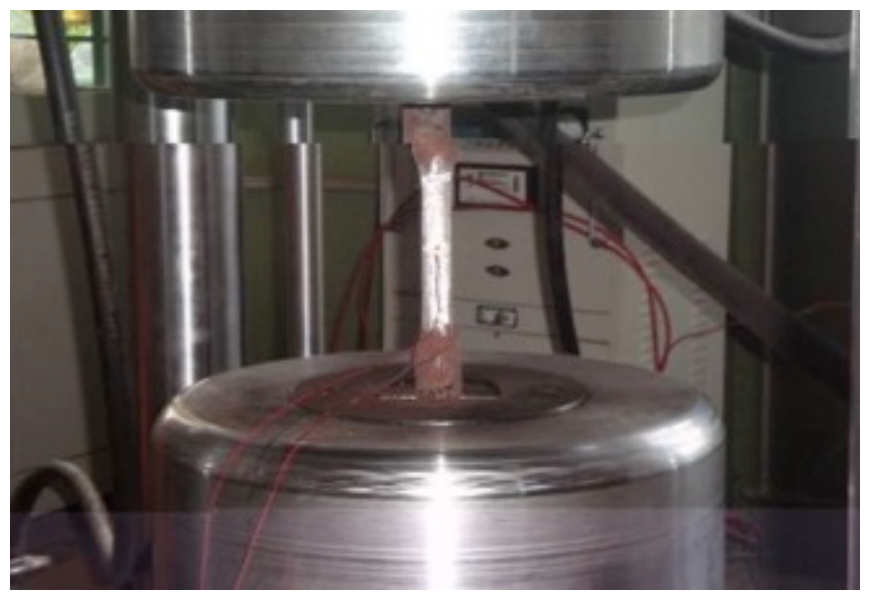

Fig. (3). The rig of material test.

\section{PREFABRICATION OF FATIGUE SURFACE CRACKS}

To know where the surface crack will come into being beforehand, before fatigue test, the stress distribution around the weld toe of tubular T-joints should be tested. 8 groups of strain gages are sticked around the weld toe (as shown in Fig. 4). Each group includes 2 strain gages, and the location of strain gage is determined according to CIDECT design guide [8].

The hot spot stress distribution curves are shown in Fig. (5). The point $0^{\circ}$ is defined at the crown position of tubular joint. It can be seen that the hot spot stress of the two specims both appear at the $180^{\circ}$ position from Fig. (5), and it can be concluded that the fatigue surface cracks will come into being at this position.

Sine wave load control method is adopted to apply the fatigue load for tubular T-joint. The specific loading scheme is shown in Fig. (6). The peak value load of sine wave curve is determined by the maximum hot spot stress, and the value should not exceed the yield stress. The position and detail dimensions of fatigue cracks are shown in Fig. (7). Where, ' $2 c$ ' is the length of cracks, and ' $a$ ' is the depth of the deepest position of cracks.
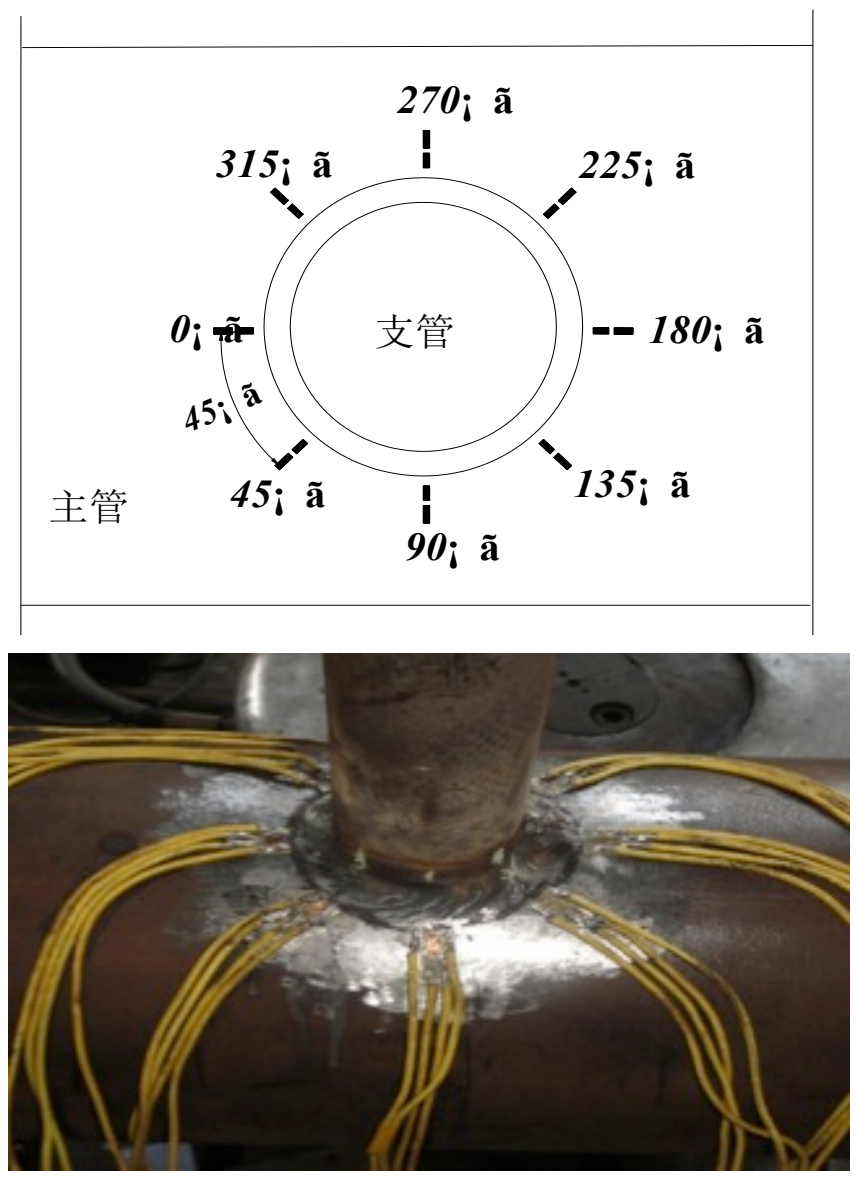

Fig. (4). Arrangement of strain gauge. 


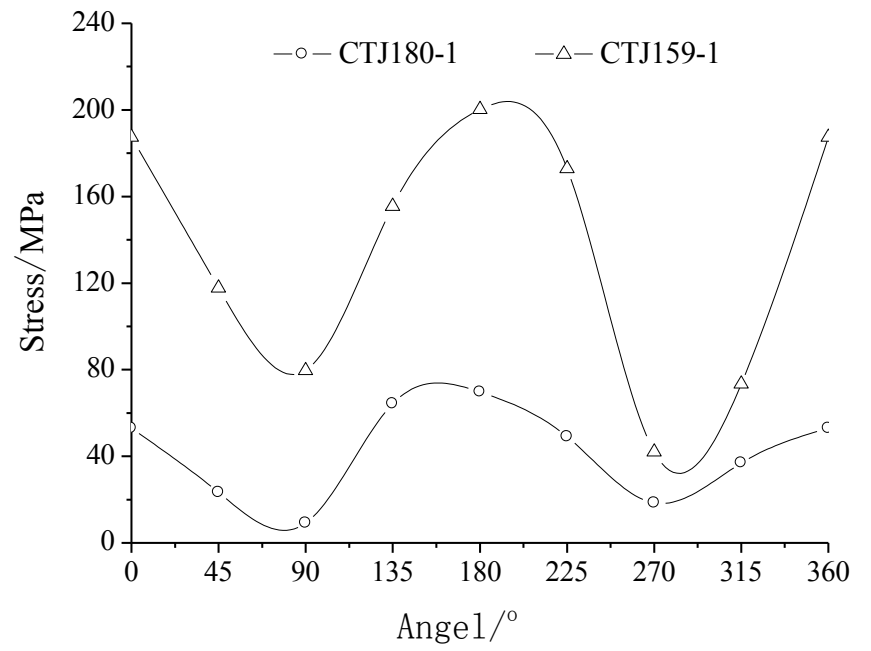

Fig. (5). Hot spot stress distribution around the weld toe of T-joints.

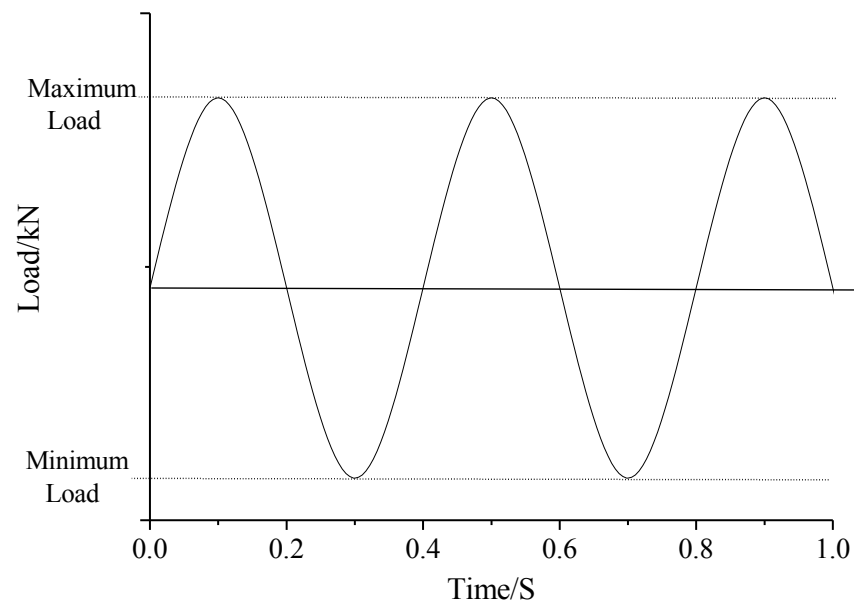

Fig. (6). Loading scheme of fatigue test.

\section{STATIC STRENGTH TEST}

After the fatigue test, the static strength tests of tubular T-joints are carried out. The SDS500 test rig will be used to tension the specimens which have been prefabricated the fatigue surface cracks (as shown in Fig. 8). The constraint conditions of specimens remain unchanged. In the course of test, the load control method is used in elastic stage, and the speed of loading is $5 \mathrm{kN} / \mathrm{min}$. When the specimens come into plastic stage, the displacement control will be used, and the speed of loading is $2 \mathrm{~mm} / \mathrm{min}$.

\section{ANALYSIS OF EXPERIMENTAL RESULTS}

The failure modes of the two specimens without fatigue surface cracks are shown in Fig. (9). It can been seen that the chord of M-B1 specimen occurs larger bending deformation, due to that the chord of specimen with larger value of $\beta$ $(0.739)$ is of stronger resistivity in the radial direction. For M-A1 specimen, due to that the value of $\beta(0.28)$ is relatively small, the larger local plastic deformation appears on the surface of chord around the weld toe. Though the failure position and state are different, the failure modes of the two intact tubular $\mathrm{T}$-joints are both overall plastic ultimate strength failure under axial tension (a) M-A1

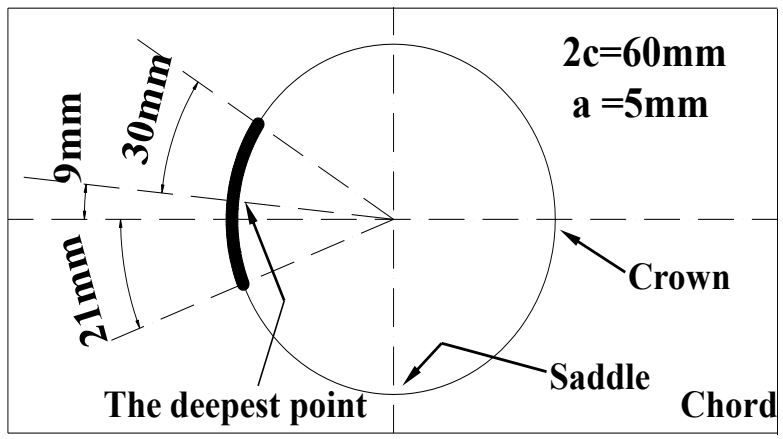

(b) $\mathrm{M}-\mathrm{B} 1$

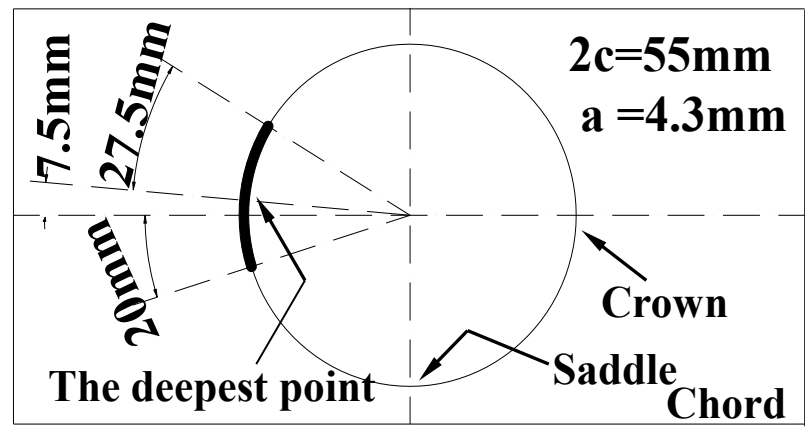

Fig. (7). Details of fatigue cracks.

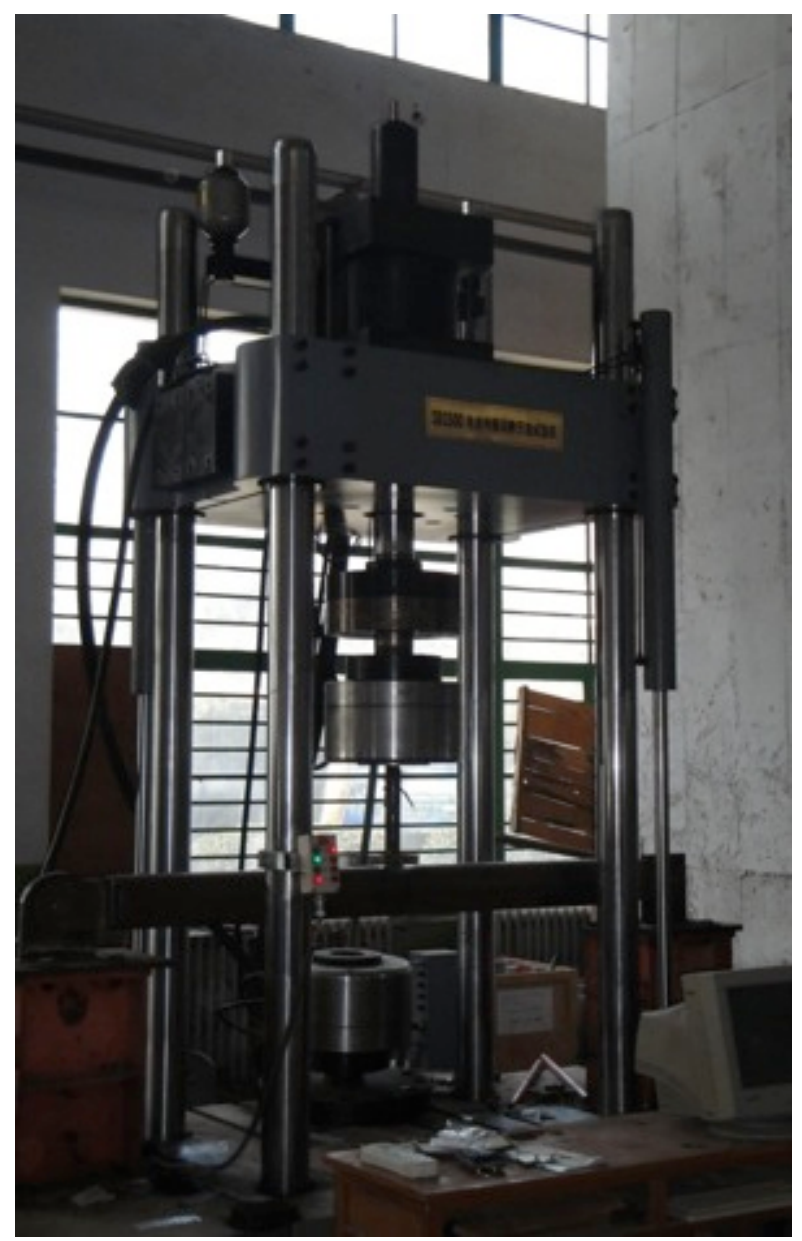

Fig. (8). SDS500 test rig. 
Fig. (10) shows the failure modes of specimens with fatigue surface cracks. For the M-A2 and M-B2 specimens, due to the existence of crack, the cracked side of specimen appears plastic range firstly. With the increasing of loading, another side of it also appears plastic range. When the loading reaches a critical value, the fatigue surface crack fractures suddenly, and it performs brittle failure. Thus, the stiffness of cracked side declines, which causes that the bearing capacity also declines (as shown in Fig. 8). Based on experimental observation, the failure modes of the two specimens are brittle fracture failure eventually and the cracks propagates alone the radial direction of the chord wall.

(a) M-A1

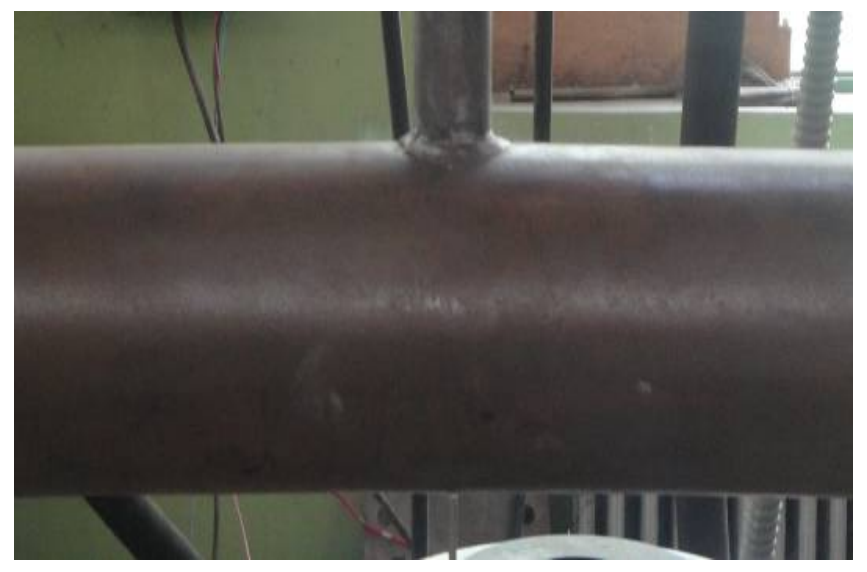

(b) M-B1

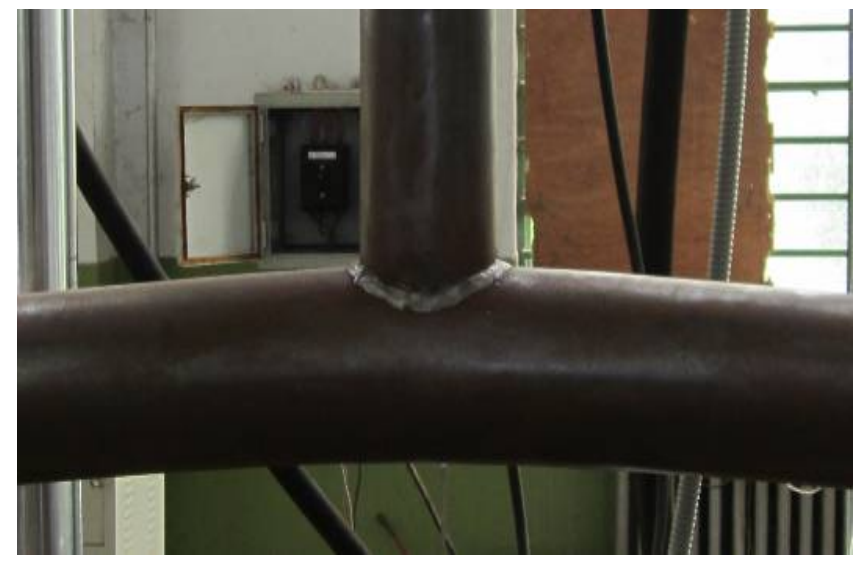

Fig. (9). Failure modes of intact specimens.

The load-displacement curves of specimens are shown in Fig. (12). It can been seen that the load-displacement curves of cracked specimens are coincident with that of uncracked ones before arriving ' $A$ ' point loading, which illustrates that the fatigue surface cracks have little effects on the static strength of tubular joints during this phase. When the loadings arrive ' $A$ ' point, the fatigue surface cracks propagate rapidly and suddenly, and then penetrate the chord wall. The stiffness of cracked specimen begins to decline, which causes that the bearing capacity decreases. Thus, 'A' point loading is a critical loading for the cracked specimen. The twice-elastic-slope (TES) method [9] is used to determine the ultimate strength of the specimens (as shown in Fig. 11). The bearing capacities of M-A specimens with and without fatigue surface are $124.6 \mathrm{KN}$ and $131.9 \mathrm{KN}$ respectively, and that of M-B specimens are $204.9 \mathrm{KN}$ and $222.3 \mathrm{KN}$ respectively. From the above dates, it can be found that the bearing capacities of the two specimens have been decreased by $5.53 \%$ and $7.8 \%$ respectively. Which indicates that the bearing capacity of tubular joint can been weakened by fatigue surface cracks.

(a) M-A2

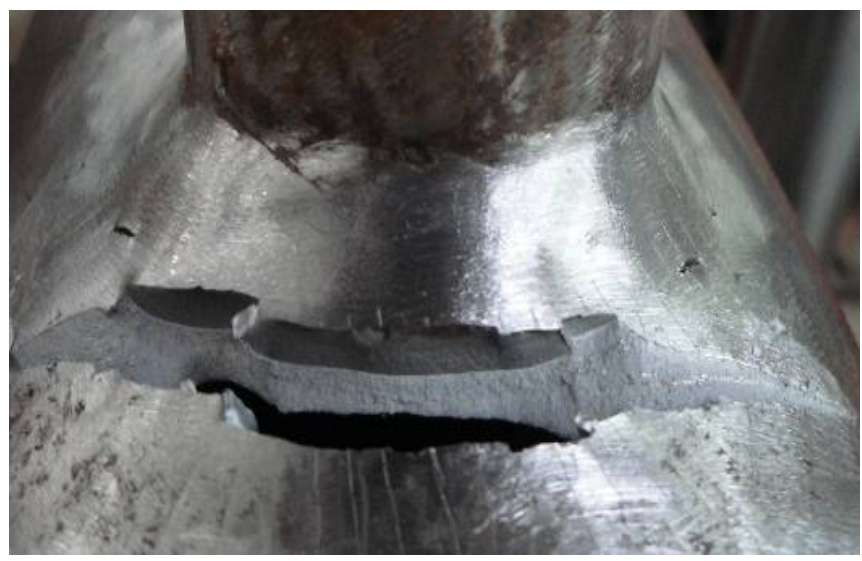

(b) M-B2

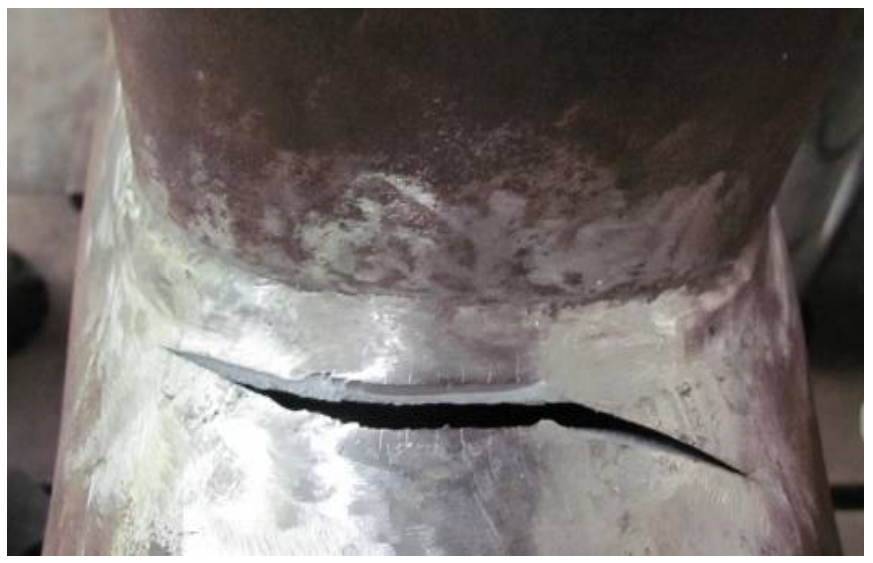

Fig. (10). Failure modes of specimens with fatigue surface cracks.

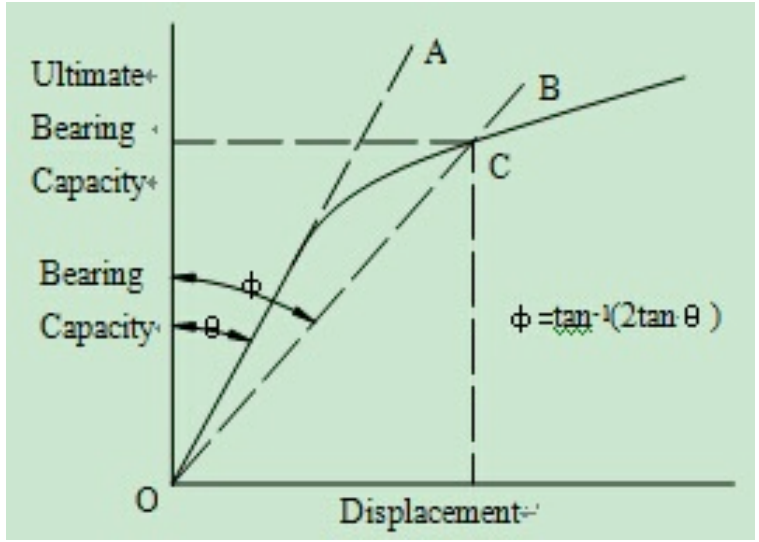

Fig. (11). TEScriteria.

\section{VALIDATION OF COMPUTATION FORMULA}

The plastic collapse loads of tubular T-joint with surface cracks can be obtained by multiplying the strength of 
(a) M-A

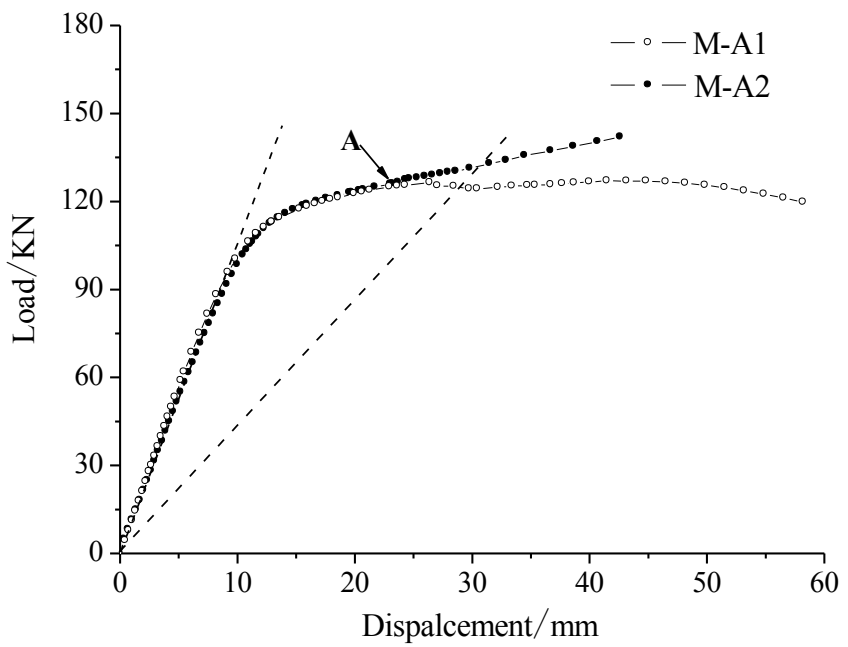

(b) M-B

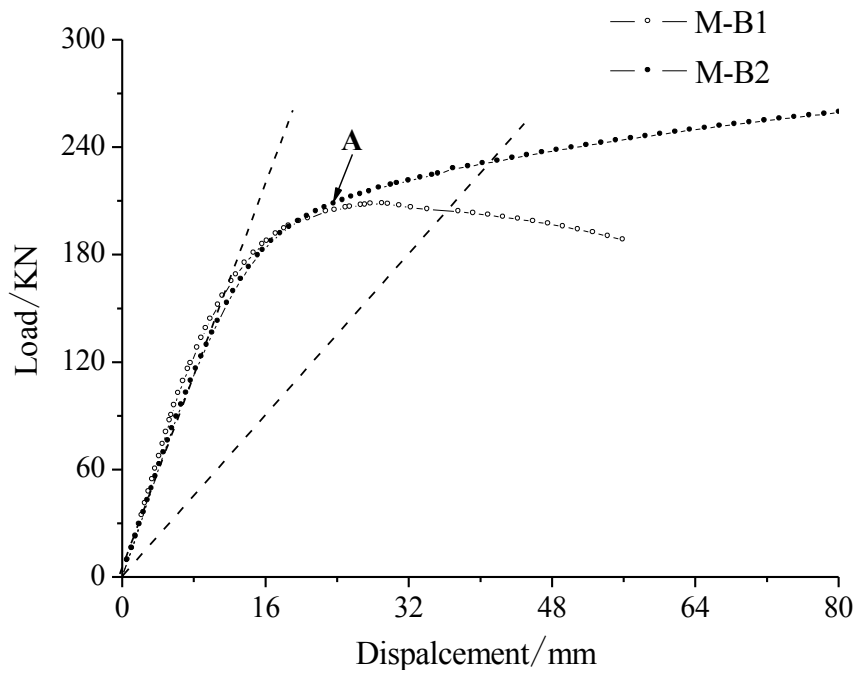

Fig. (12). Load-displacement curves of the specimens.

equivalent uncracked joint by an 'area reduction factor'(ARF) [10]. The computation formula of ARF is as follows:

$F_{A R}=\left(1-\frac{A_{\text {crack }}}{T \times \text { weld length }}\right)\left(\frac{1}{Q_{\beta}}\right)$

where, $A_{\text {crack }}$ is the area of crack surface, $\mathrm{T}$ is the thickness of chord wall, and $Q_{\beta}$ is a coefficient related to $\beta$, as shown in formula (2).

$$
\begin{cases}Q_{\beta}=1.0 & (\beta \leq 0.6) \\ Q_{\beta}=\frac{0.3}{\beta(1-0.833 \beta} & (\beta>0.6)\end{cases}
$$

The weld length is a space curve, and its function expression is very complex. The intersecting line parameter equation is shown in formula (3).

$$
\left\{\begin{array}{l}
\mathrm{X}=\mathrm{R} \cos \left(\arcsin \left(\frac{\mathrm{r}}{\mathrm{R}} \sin \alpha\right)\right) \\
\mathrm{Y}=\mathrm{r} \sin \alpha \\
\mathrm{Z}=\mathrm{r} \cos \alpha
\end{array}\right.
$$

The above formula is calculated by curvilinear integral, and the calculation formula of intersecting line's length is obtained. Due to that the effect of weld size is very great, the weld size should be considered as an important factor to calculate the length of intersecting line. The calculation formula of intersecting line's length is shown in formula (4).

$L=\int_{0}^{2 \pi} \sqrt{\frac{\left(r+t_{w}\right)^{4} \sin ^{2} \alpha \cos ^{2} \alpha}{R^{2}-\left(r+t_{w}\right)^{2} \sin ^{2} \alpha}+\left(r+t_{w}\right)^{2} d \alpha}$

where, $r$ is the radius of brace, $R$ is the radius of chord, tw is the weld size, $\alpha$ is the angel of brace and chord, $L$ is the length of intersecting line.

Based on the above formula and the measured value of geometric dimension of specimens, the values of every parameter are calculated and listed in Table $\mathbf{3}$.

Table 3. The results of parameters.

\begin{tabular}{|c|c|c|c|c|}
\hline Model & $\boldsymbol{L}(\boldsymbol{m m})$ & $\boldsymbol{A}_{\text {crack }}\left(\boldsymbol{m}^{2}\right)$ & $\boldsymbol{T}(\boldsymbol{m m})$ & ARF \\
\hline \hline M-A & 213.03 & 175.71 & 8 & 0.8969 \\
\hline M-B & 515.98 & 184.63 & 8 & 0.9012 \\
\hline
\end{tabular}

The values of ARF are calculated by the above formula (As shown in Table 4), and the bearing capacities are also all listed in Table 4. Where, $F_{u}$ is the bearing capacity of uncracked specimens; $F_{f}$ is the bearing capacity of cracked specimens calculated by 'ARF' method; $F_{c}$ is the bearing capacity of cracked specimens; $P$ is the percentage of the difference between testing and calculating by formula for tubular T-joint with surface cracks.

Table 4. The results of testing and computation.

\begin{tabular}{|c|c|c|c|c|}
\hline Model & $\boldsymbol{F}_{u}(\mathbf{K N})$ & $\boldsymbol{F}_{f}(\mathbf{K N})$ & $\boldsymbol{F}_{c}(\mathbf{K N})$ & $\boldsymbol{P}$ \\
\hline \hline M-A & 131.9 & 118.3 & 124.6 & $5.3 \%$ \\
\hline M-B & 222.3 & 200.07 & 204.9 & $2.5 \%$ \\
\hline
\end{tabular}

From datum of Table 4, it can be found that the percentages of the difference between testing and calculating by formula for the two tubular T-joints with surface cracks are both less than $6 \%$, and it is in an acceptable range. Thus, 
it is reliable and acceptable that the computing formula of 'ARF' method is used to calculate the static strength of tubular T-joints with fatigue surface cracks.

\section{CONCLUSION}

Based on the analysis of tubular T-joint with fatigue surface crack under axial tension by experimental investigate method, the following conclusions can be drawn.

1) The failure mode of uncracked tubular $\mathrm{T}$-joint is overall plastic ultimate strength failure. However, the failure mode of tubular T-joint with fatigue surface crack is brittle fracture failure eventually, and the crack propagates alone the radial direction of the chord wall.

2) The stiffness of the cracked tubular joint is not influenced by the fatigue crack greatly in linear and elastic stage.

3) The residual strengths of the cracked tubular T-joints decrease by $5.53 \%$ and $7.8 \%$ respectively compared with corresponding uncracked tubular T-joint. It indicates that the bearing capacity of tubular joint can been weakened by fatigue surface cracks.

4) It is reliable and acceptable to calculate the static strength of tubular T-joints with fatigue surface cracks by the computing formula of 'ARF' method.

\section{CONFLICT OF INTEREST}

The authors confirm that this article content has no conflict of interest.

\section{ACKNOWLEDGEMENTS}

The authors appreciate the support of the science and technology project of Jiangsu construction system.

\section{REFERENCES}

[1] Y. Yang, "Experimental study on the behavior of tubular T-joint containing fatigue crack", J. Zhengzhou Eng. Instit., vol. 13, pp. 42-46, 1992.

[2] U. Zerbst, J. Heerens, and S. KH, "The fracture behaviour of a welded tubular joint - an ESIS TC1.3 round robin on failure assessment methods Part I: experimental data base and brief summary of the results", Eng. Fract. Mech., vol. 69, pp. 10931110, 2002.

[3] G. W. Marshall, and R. A. Ainsworth, "The fracture behaviour of a welded tubular joint - an ESIS TC1.3 round robin on failure assessment methods Part II: R6 analysis", Eng. Fract. Mech., vol. 69, pp. 1111-1118, 2002.

[4] F.M. Burdekin, "The fracture behaviour of a welded tubular joint an ESIS TC1.3 round robin on failure assessment methods Part III: UK BS7910 methodology", Eng. Fract. Mech., vol. 69, pp. 1119$1127,2002$.

[5] U. Zerbst, R. Primas, H.J. Schindler, J. Heerens, and K.H. Schwalbe, "The fracture behaviour of a welded tubular joint - an ESIS TC1.3 round robin on failure assessment methods Part IV: application of the ETM 97/1", Eng. Fract. Mech., vol. 69, pp. 1129-1148, 2002.

[6] H. J. Schindler, R. Primas and M. Veidt, "The fracture behaviour of a welded tubular joint - an ESIS TC1.3 round robin on failure assessment methods Part V: screening method by required toughness and plastic stability considerations", Eng. Fract. Mech., vol. 69 , pp. 1149-1160, 2002.

[7] U. Zerbs, T. Miyata, and M. Veidt, "The fracture behaviour of a welded tubular joint - an ESIS TC1.3 round robin on failure assessment methods Part VI: application of WES 2805-1997”, Eng. Fract. Mech., vol. 69, pp. 1161-1169, 2002.

[8] X. L. Zhao, S. Herion, J.A. Packer, R. Puthli, G. Sedlacek, J. Wardenier, K. Weynand, A. van Wingerde, N. Yeomans, Design Guide for Circular and Rectangular Hollow Section Joints Under Fatigue Loading, CIDECT, TUV, Germany, 2000.

[9] ASME Boiler and Pressure Vessel Code, Sec. III, Division 1, Subsec. NB, Sec. NB-3213, NY: American Society of Mechanical Engineers, 2005.

[10] The Static Strength of Cracked Tubular Joints: New Date and Models, United Kingdom: HSE Books, 1999.

(C) Wei and Song; Licensee Bentham Open.

This is an open access article licensed under the terms of the Creative Commons Attribution Non-Commercial License (http://creativecommons.org/licenses/by-nc/3.0/) which permits unrestricted, non-commercial use, distribution and reproduction in any medium, provided the work is properly cited. 